\title{
Application Analysis of Hand-painted Performance Techniques in Environmental Art Design
}

\author{
Rong Yang \\ Xi’an Peihua University, Xi’an, Shaanxi, 710125
}

Keywords: hand-painted performance; environmental art; application analysis

\begin{abstract}
Hand-painting is a means of expressing physical things through painting, which plays an important role in the design of environmental as art performance techniques. Compared with computer graphics, hand-painting performance is more unique, and it can express design thinking in an emotional manner, and can not only capture the inspirational moments of electro-optics and stone fires, but also draw them out through the ideal graphics in the mind and fully express the designer's intrinsic inspiration and cultural and artistic qualities. Although modern information technology is continuously advancing and developing, hand-painting performance still plays an important role in environmental art design. It is an irreplaceable drawing method for designers, and for environmental art designers, maturely embodies the content of ideas in practice. Based on the definition, characteristics, value, style and application of hand-painting expression, this paper discusses and analyzes the hand-painting art form in environmental art design.
\end{abstract}

\section{Introduction}

Hand-painting refers to an art form that is hand-drawn by environmental art designers in the environmental art design and expressed using hand-drawn drawings. At the same time, it also integrates science, culture, and descriptiveness, and can be used to design designers in a short period of time. The design intent and design scheme are expressed accurately and conveniently. It is an effective way for many environmental art designers to analyze and compare design solutions and to present creative design works. In the environmental design art, the design effect of the hand-painted effect is determined by the level of the hand-painted expression technique. Designers can use space composition and perspective, line and shape to enhance training, so that their hand-painted performance skills and skills can be improved. There are many types of techniques for hand-painted expression. Designers need to have a solid background in painting, and they should also have the inspiration to create a hand-drawn drawing that is beautiful and yet attractive.

\section{Characteristics of Hand-painting Performance Techniques in Environment Art Design}

In the hand-painted performance of environmental design, it will be based on the spatial structure of the things in the specific environment, terrain, color changes, materials, and the strength of light and other factors to truly depict, and show a certain degree of artistic expression, which is The so-called realistic simulation. It is the basic characteristic of the hand-painted expression form. It can show the skill and imagination of the designer's freehand drawing, and it can not only truly show the impression of the work. Because there are differences in the forms of expression and methods, there will be different performance effects and scenes.

However, one thing to note is that "reality simulation" is not equivalent to "realistic reality." Because the hand-painted performance of environmental art is expressed by the designer's own concept, the "realistic simulation" expresses the fact that the elements existing in the environment are described and expressed according to the objective reality. At the same time, there are certain design expression factors that infiltrate, and are not exactly equivalent to purely painted forms.

After realizing the design of environmental art, the designer should clearly express and explain the overall and local aspects of the plan, especially the details of the shapes, colors, structures, and processes, so that not only The customer has more convenient and clearer understanding of the 
drawing content, and can also provide a reliable reference and basis for further implementation of the item.

Based on the realistic simulation performance, the author expresses creativity and conceptuality. Through the refinement of thinking and the imagination of spatial thinking, the specific physical objects of the desired performance environment design are expressed using abstract graphic concepts. This is called creative expression. This is an important feature of the hand-painted performance of environmental design.

Environmental design hand-painted performance is a process in which the designer's brain uses his or her own intentions to make use of drawing drawings. It can accurately grasp the overall effect of the design scheme, and it can also act as a communication and recognition of the design scheme. effect. We must not only focus on the actual conditions actually present in environmental design, but also summarize and analyze and integrate the existing conditions of existence. We can complete the expression of abstract concepts by thinking and imagining and using the drawing of graphs. The main method of performing creative performance.

Innovation is the soul of design. The current environmental design has a variety of hand-painted expression methods. Its different performance purposes will lead to some differences in methods and formal languages, and innovation can accomplish the purpose of expressing unique design styles and expressing personal characteristics. Designers can combine "new" and "interesting” in the process of environmental design to focus on the intention of innovation and the overall effect of drawing. The designer's own subjective thinking can be used to depict and describe the specific circumstances of environmental design. Unique aesthetic features.

In the environmental design hand-painted performance, designers usually use the most convenient tools and materials, and express their design intent through simple image design characters or graphic symbols. This feature is the so-called intuitive simplicity, which is in the environmental art. Has played a role in making people easy to read and understand.

The intuitive simplicity of the hand-painted representation of the environmental design plays a direct and decisive role in the important position between the drawing of the environmental design and the real painting of the environment design. In the process of expressing environmental elements, designers should discard other unnecessary details to prevent interference with the design theme and firmly grasp the typical and representative features of the environmental design performance objects. The essence of things must be grasped in order to avoid being overly rigid and truly depicted. In the actual environment art design project, the environmental art design drawing should be read by professionally trained people, and the environmental art design hand-painted performance is demonstrated by using the most intuitive performance elements such as points, lines, surfaces, etc., which can easily make People have a clearer and clearer understanding of the design concept.

The so-called "dimensional expressiveness" refers to the designer's hand-painted representation of environmental design. In order to facilitate communication with people, the designer usually combines the main points of the design idea with some representative thinking steps or detailed drawings and main performance diagrams. expression. This feature of environmental art design can facilitate other people to understand and accept the designer's purpose more clearly.

\section{The Value of Hand-painting Performance Techniques in Environment Art Design}

With the development and progress of social economy, people have also put forward higher requirements for the design of the space environment they live in. Designers should not only pay attention to the formal beauty of space design and the use of basic functions, but also present and express their personalized concepts and design styles to users in a short period of time so that customers can more quickly Have a good understanding of the designer's design concept, and accept the designer's design plan with satisfaction. Therefore, the designer should master the hand-painted performance skills. Through the hand-drawing, the communication time between the designer and the client can be reduced. At the same time, the satisfaction of the client and the design of the designer can also be the design of the designer. The success rate of the plan is improved. 
When designers express their designs expressively, they can also make customers more profoundly and intuitively realize the attractiveness of the design solutions, so they have potential market value.

Hand-painted renderings not only have high market value, but also have certain artistic value. Hand-painted expressions have a variety of expressions, any form of expression has a unique viewing effect, and sometimes these art forms can be used to decorate beautiful decorations. Hand-painted renderings as a unique art style have invaluable artistic value.

\section{Common Forms of Hand-painting Performance Techniques in Environment Art Design}

Sketching is one of the most basic capabilities of hand-painted expressions, but it plays a decisive role in the design of reality. Some hand-painted designers can make full use of the convenience, randomness and artistic spirit of sketch hand-drawing to bring out the designer's own inspiration or artistic originality. The convenient and quick features and intuitiveness of sketching can make the design work more directly presented to others. The creative process can be divided into three links. The first link is the collection of information. This link can be completed with a digital camera or mobile phone. The second link is the analysis of information. The last link is to solve the problem. The program. The second and third links are the key to the entire creative process. Due to the need for recording and analysis, it can be done with hand-drawn functions such as sketches, sketches, illustrations, or visual notes. In the design of a project, the designer vividly shows the design scheme that they want to study by hand drawing.

In the design of environmental art, the expression of hand drawings of various types of works sometimes requires the use of sketches. Sketching plays an extremely important role in the process of environmental art design. There are some differences between it and sketching of pure hand-painted art. First, the role of sketching in design is to collect data, record and analyze the observation objects. Design sketching tends to be more visually oriented. Sketching reflects and records the initial impressions and thoughts about the site environment and the characteristics of the area. They provide topographic, hydraulic, and urban scientific research that can reflect the context and context of the project plan. The main factor. Therefore, in the realistic environmental art design, sketching can more show the designer's aesthetic ability and art skills.

\section{Hand-painting Performance Techniques in Environment Art Design}

There are many application methods in the hand-painted renderings, among which are the pen technique, the watercolor brush technique, the marker pen technique, the color pen technique, and the comprehensive expression technique. The following combination of practical operation will introduce a variety of techniques.

The pen-and-ink technique is a hand-painted technique from the West that can directly display visual experiences. Some important factors in pen-and-ink techniques are the line drawing of pens, the darkness of pens, and the rapid performance of pens. The line of the pen is the soul element of the pen drawing, which determines the quality of a picture, requires the lines to be smooth, reasonable and beautiful; the combination of the lines should be a sound summary of the target scene, and plays a role in the whole work. The key role in the process of drawing should be to pay attention to the low intensity of gripping, to be able to draw a line, and to avoid drawing back and forth; for relatively long lines, it can be segmented.

The performance of pen and ink is very strong. For students who have just come into contact with pen and ink, they must practice from the basic good pen lines, and continue to practice, so that the level of their own pen paintings can reach a comfortable level.

As a designer's most commonly used art hand-drawn form, the reason why it can be favored by designers is because it has different characteristics from other hand-drawn methods - transparency, easy drying and rich colors, etc. It can also be combined with other hand-drawn forms, thus enriching the performance level of the design drawings.

Environmental art design drawings are often based on a single hue as the basis of color, and the appearance of watercolors has led to an innovation in the environmental art design, enriched the 
design of the color, from a single color to a variety of colors, these Different color areas also use different ways of labeling. The coloring process is an indispensable link in watercolors, and it is necessary to impose training on them. In the process of coloring, attention should be paid to the area where the coloring is to be done, and no space should be left. At the same time, attention should be paid to the uniformity of coloring. Therefore, it is necessary to grasp it. Write down.

The marker, also known as the pen, is a tool for rapid painting. It can be divided into two types. One is a single head that can quickly outline the design to be designed and the design area; the other is a flat head that can quickly color the design area. This type of writing head can quickly Express the designer's design intent. The marker can also be used with whiteboard paper. The surface of the whiteboard paper is smooth and the lines drawn on the paper are smooth and rounded.

Color pencils are generally water-soluble. This color pen technique has a relatively strong fusion. The carbonaceous part of the pencil is softer, easily tolerate water, and has a lot of flexibility. In the process of drawing the design drawings, the colored pencils generally function as auxiliary drawings and can be used in place of the excellent colors brought by the markers.

The so-called comprehensive performance technique, as the name implies, is a technique that combines a variety of hand-painted methods, through a combination of multiple techniques can maximize the inspiration of designers' ideas. Designers should use different hand-drawn methods to create designs according to their own design concepts and design drawings, and use the most reasonable methods to complete the drawing. Comprehensive performance techniques require the designer to have a spirit of innovation and to keep pace with the times, so that design drawings and current social development can advance with the times, so that the design can achieve its maximum effect.

\section{Application of Hand-painting Performance Techniques in Environment Art Design}

In the teaching of environmental art design, the main applications of hand-painting are: random records, sketches, design drawings, predictions, etc.

In the design conception stage, hand-drawn sketching runs through the entire process of the design. Hand-drawn sketches are the integration of the most effective and convenient thinking in the initial stage of the design scheme. The design of the scheme cannot leave the use of the sketch because the design The production of sketches is a process of subjective and objective image thinking and performance in design work, and it is also a process of rational analysis of figures. Sketches are the beginning of hands-on design. The process of sketching is also a process of comparing, deliberating, and deepening the design concept, and promoting the gradual progress of the design scheme. The formation of the plan is realized by design drawings and prediction plans.

The hand-drawn quick-prediction map is combined with the perspective principle to analyze, reproduce the real scene of the object, and use different expression methods according to the needs of the design content, such as a marker pen, transparent water color, color lead, etc., which requires the designer not only to be flexible The spatial thinking ability, but also requires superb performance of the object. It is expected that the drawing will be influenced by the artist's own artistic temperament and cultivation. Different visions, techniques, and styles are predicated on the designer's personality. Designers can comprehend and draw all the design drawings through their own spirituality and feelings, and then express their effects through their own artistic language. This makes the stylized and constrained design drawing embody sensual sentiment and unique artistic charm. Therefore, learning to be good at hand-painting can not only improve the thinking ability of the designer, but also improve the visual technology, and at the same time, it can visually and vividly create the visual effect of the screen.

\section{Conclusion}

The artistic performance techniques of environmental design have continued to be optimized and changed with the continuous development of China's design industry and the improvement of people's aesthetic standards. Although hand-painted techniques do not play a major role in modern 
environmental art design, they also have a certain influence on the performance of art design. We should continue to innovate in the form of hand-painting based on the changes of today's times. At the same time, we should also draw on the essence of traditional hand-painted techniques to keep up with the times. In today's rapid development of information, it should be organically combined with hand-painted techniques and computer design to show the unique charm of hand-painted forms. In short, designers should continue to tap and innovate, and be familiar with mastering hand-painted performance techniques to promote the development of environmental art design.

\section{References}

[1] Wang Wenzeng, Hou Geying. Application of Hand-painted Performance Techniques in Environmental Art Design [J]. Literary Life • Mid-term Journal, 2017(2).

[2] Bi Huijuan. Research on the Role of Hand-painted Performance Techniques in Environmental Art Design[J]. Interior Design \& Finishing, 2016(5).

[3] Xiao Binmei, Zou Jialiang, Xiao Fuyan, et al. The role of hand-painted performance techniques in the art design profession [J]. Art Review, 2017(20): 157-160.

[4] Liu Yin. Application of Hand-painted Expression in Environmental Design and Design[J]. Guangdong Economy, 2017(16).

[5] Han Xu. Hand-painted performance 